\title{
Opioid-Induced Constipation in Oncological Patients: New Strategies of Management
}

Ricard Mesía, $M D^{1}$

Juan Antonio Virizuela Echaburu, $M D^{2, *}$

Jose Gómez, $M D^{3}$

Tamara Sauri, $M D^{4}$

Gloria Serrano, $M D^{5}$

Eduardo Pujol, $M D^{6}$

\author{
Address \\ ${ }^{1}$ Servicio de Oncología Médica, Instituto Catalán de Oncología, Badalona, Spain \\ ${ }^{*}, 2$ Servicio de Oncología Médica, Hospital General Universitario Virgen Macarena, \\ Seville, Spain \\ Email: javirizuelae@seom.org \\ ${ }^{3}$ Hospital la Fe, Valencia, Spain \\ ${ }^{4}$ Hospital Clinic de Barcelona, Barcelona, Spain \\ ${ }^{5}$ Hospital Infanta Leonor, Madrid, Spain \\ ${ }^{6}$ Hospital Clínico Lozano Blesa, Zaragoza, Spain
}

Published online: 19 December 2019

(C) The Author(s) 2019. This article is an open access publication

This article is part of the Topical Collection on Palliative and Supportive Care

Keywords Cancer • Opioid-induced constipation - Opioid analgesics · Pain · Naloxegol · Laxatives

\section{Opinion statement}

Cancer-associated pain has traditionally been treated with opioid analgesics, often in escalating doses. Opioid-induced constipation (OIC) is a common problem associated with chronic use of opioid analgesics. Typical treatment strategies to alleviate constipation are based on dietary changes, exercise, and laxatives. However, laxatives have a nonspecific action and do not target underlying mechanisms of OIC. This article will review prevalent, clinical presentation and recommendations for the treatment of OIC. An independent literature search was carried out by the authors. We reviewed the literature for randomized controlled trials that studied the efficacy of laxatives, naloxone, and naloxegol in treating OIC. Newer strategies addressing the causal pathophysiology of OIC are needed for a more effective assessment and management of OIC. Finally, traditional recommended therapies are appraised and compared with the latest pharmacological developments. Future research should address whether naloxegol is more efficacious by its comparison directly with first-line treatments, including laxatives. 


\section{Introduction}

Pain is one of the most common symptoms related with cancer and its treatment [1]. Pain prevalence in patients is $33 \%$ after curative treatment, 59\% during curative treatment, and $64 \%$ in patients with metastases or in advanced stage disease. A multicenter study in Spain has demonstrated that approximately 55\% of all cancer patients suffer from pain [2]. Pharmacotherapy, especially opioids, is the principal modality for managing chronic pain in cancer patients. This type of therapy could be related with different adverse effects in these patients. Opioid-induced bowel dysfunction (OIBD) is a frequent complication of long-term opioid treatment, which affects $40-80 \%$ of patients treated with opioids. It can cause reduced quality of life (QOL) and insufficient treatment of pain [3]. Opioid-induced constipation (OIC) is the most frequent and bothersome symptom, it affects 60 to $90 \%$ of cancer patients with opioids [4], between $10 \%$ and $20 \%$ of the population experiencing constipation at baseline; however, some of them develop it because of the opioids (OIC), but, in others, constipation is an exacerbation of the preexisting one (opioid-exacerbated constipation, OEC) [5]. Traditional treatment strategies to alleviate constipation, such as laxatives, are also used to manage OIC; however, laxatives do not address the underlying opioid receptor-mediated cause of OIC and are often ineffective. A novel approach for selectively and locally antagonizing the gastrointestinal effects of opioids involves the coadministration of a peripherally acting $\mu$-opioid receptor antagonist (PAMORA) with negligible availability to the central nervous system (CNS), such as oral naloxegol.

\section{Materials and methods}

An independent literature search was carried out by the authors (during November 2017) with the abovementioned search strategy and the following details were extracted: trial site, year, trial methods, participants, interventions, and outcomes.

We conducted the review protocol using the Preferred Reporting Items for Systematic Reviews and Meta-analyses (PRISMA) guidelines. We used the following search protocol in PubMed: ("Opioid-induced constipation" [All Fields] OR ("Opioid-induced constipation" [Supplementary concept]) OR ("cancer and constipation" [Supplementary concept] OR "cancer and constipation" [All Fields] OR ("Opioid-induced bowel dysfunction" [Supplementary concept] OR "Opioid-induced bowel dysfunction" [All Fields] OR "laxatives" [All Fields]) OR ("laxatives" [Supplementary concept] OR "naloxegol" [Supplementary concept] OR "naloxegol" [All Fields]).

We reviewed the literature for randomized controlled trials that studied the efficacy of laxatives, naloxone, and naloxegol in treating OIC.

The articles were selected following these preferences: English language, human and animal studies, and research support. Case reports have been excluded from this review. The retrieved studies were screened for inclusion and exclusion criteria.

\section{Results}

After applying our research protocol, 83 publications were identified, 20 of which were clinical trials. Also, taken into account were observational studies on laxatives, naloxone, and naloxegol in patients with OIC, in different environments. 
The current review starts by providing a brief overview of the pathophysiological mechanisms whereby opioids modify GI function. After addressing the use of laxatives and opioid receptor antagonists for treatments of OIC, the article goes on to discuss emerging strategies to avoid OIBD and the clinical utility of PAMORAs.

\section{Pain and cancer}

Advanced cancer patients frequently suffer from pain at all stages of the disease, during active treatment, during metastatic stage disease, and after the cancer had been cured. Pain is undertreated in 31 to $65 \%$ of these patients, although adequate pain relief is considered feasible in $86 \%$ of patients with cancer [6]. Although reports vary widely, the range of reported prevalence of pain is highest for the following tumors: head and neck (67-91\%); prostate (56-94\%); uterine (30-90\%); genitourinary (58-90\%); breast (40-89\%); pancreatic (72-85\%); gastrointestinal (44-74\%); and lung/bronchus (44-67\%) [7].

The cause of pain is a verifiable lesion or disorder that is likely to produce pain through direct tissue injury or through a related process, such as inflammation [8]. Overall, 3 in 4 patients suffer from cancer-related pain while most of the remaining pain syndromes are caused by disease-modifying therapy. Mucosal pain that affects diet occurs during active cancer therapy and is a common chronic complaint in survivors that affects diet and QoL [9].

Opioid analgesics have a significant role to play in the management of chronic pain. They are therefore integrated with strategies that include an interventionist, psychological, physical, or complementary focus to improve the treatment of pain, enabling rehabilitation [10]. Common adverse effects to opioid treatment include nausea, headache, confusion, and gastrointestinal (GI)-related symptoms [11].

\section{Opioid-induced bowel dysfunction and constipation}

GI-related symptoms, normally referred as (OIBD), are the most common and bothersome adverse events of opioid treatment. Up to $80 \%$ of patients who receive opiates experience OIBD symptoms such as dry mouth, nausea, acid reflux, loss of appetite, abdominal pain, bloating, and symptoms related to constipation (OIC) [3].

OIBD symptoms are mediated by opioid interaction with peripheral $\mu$ opioid receptors located at the gastrointestinal tract. Enteric opioid receptors (predominantly $\mu$ and $\delta$ ) are located in the submucosal and myenteric plexus, respectively, in addition to immune cells in the lamina propria of the cellular wall. The activation of these receptors inhibits excitatory and inhibitory neural pathways within the enteric nervous system that coordinates motility. These mechanisms reduce peristaltic contractions (due to the inhibition of excitatory neural pathways), increase GI muscle activity, and elevate resting muscle tone, spasm and non-propulsive motility patterns (due to the inhibition of the inhibitory neural pathways). As a result, delayed gastric emptying and intestinal transit slowing is induced [11]. Activation of opioid receptors by opioid administration inhibits secretion of several regulatory neurotransmitters of GI tract, which leads to the discoordination of GI tract motility [12]. Spastic achalasia-like esophageal dysmotility, for instance, is the result of nonperistaltic esophageal contraction with incomplete relaxation of the lower 
esophageal sphincter after opioid administration. In the small and large intestine, these imbalances lead to increased segmental contraction and decreased propulsive forward peristalsis, which manifest clinically by constipation, gut spasm, and abdominal cramps [13]. In addition, direct activation of $\mu$-opioid receptors $(\mathrm{MOP})$ in the enteric nervous system inhibits vasoactive intestinal peptide (VIP) secretion and subsequently decreases pancreaticobiliary secretion and gut absorption and hence, harder and drier stool.

OIC prevalence rates ranged from 15 to $90 \%$ based on an analysis of 16 clinical trials and observational studies identified in patients with or without cancer [14] and from 70 to $100 \%$ among hospitalized patients. This variation may be attributable, among others, to patient population assessed, study design, and the lack of standardized definition of constipation across studies. Only few studies have described OIC in cancer patients. $62 \%$ of the patientes showed a problematic degree of constipation, according to the KnowlesEccersley-Scott symptom (KESS) score, in the DYONISOS study (DYsfonctiONs Intestinales induiteS par les OpiondS forts), a cross-sectional observational study with 520 cancer patients in France [15]. In a study carried out in Spain with 317 ambulatory patients undergoing treatment with different opioids for chronic pain, whether caused by cancer or not, $94.6 \%$ of patients reported at least one symptom of OIBD. The most frequent symptom was constipation (91.6\%). Almost half the patients reported three or more symptoms with a severity equal to or greater than 4 according to the numeric rating scale (11-point scale, from 0 to 10) [16].

Relevant impairment of QoL in patients with cancer pain and OIC has been reported. Cancer patients with OIC have significantly reduced QoL compared with those cancer patients without OIC, as measured by both the conditionspecific Patient Assessment of Constipation-Quality of Life (PAC-QOL) and the generic Short Form-12 questionnaires [15]. OIC negatively affect pain management, productivity, and patients' QoL [3] and also increase the use of healthcare resources and costs. The risk of having an all cause inpatient hospitalization, emergency department visit, and office or other outpatient visit was nearly twice higher in patients on chronic opioid treatment with OIC [15].

Recently, OIC definition has been proposed as a change, when initiating opioid therapy, from baseline bowel habits and defecation patterns that is characterized by any of the following symptoms: reduced bowel frequency; development or worsening of straining; a sense of incomplete evacuation; or a patient's perception of distress related to bowel habits [17]. Rome Foundation has endorsed such definition and included OIC as a new bowel disorder, the first OIC diagnostic criteria have been described in the new Rome IV publication. Consensus definition and diagnostic criteria for OIC are now pending adoption to guide clinical and epidemiological research and to inform treatment recommendations.

Patient reported outcome measures are also important to identify OIC. To ensure OIC assessment, patient constipation evaluation scales are recommended. The most commonly used include the Constipation Assessment Scale (CAS), Patient Assessment of Constipation Symptoms (PAC-SYM), Bowel Function Diary, and the Bowel Function Index (BFI) [18]. The American Academy of Pain Medicine along with The American Gastroenterology Association recommend using the BFI to ensure rapid and reliable assessment of OIC in clinical practice [19]. BFI is a practical and clinically responsive tool that has been validated in OIC. The BFI is responsive to changes in symptoms 
severity and across a broad range of patients. The BFI score range from 0 to 100 points, with higher scores indicating a more severe condition, and $\geq 30$ points indicating constipation. Furthermore, a BFI $\geq 30$ is considered a criterion to initiate specific pharmacological treatment such as PAMORA for patients on laxative treatment. Failure to first-line treatment should be determined rapidly to provide adequate relief to the patients with OIC [20].

A working group of experts identified the most common barriers for the diagnosis and treatment of OIC [21]. Lack of awareness among doctors about OIC in patients receiving opioid therapy, patients' embarrassment at revealing their symptoms to doctors, doctors' inability to ask the patient about constipation, the absence of universal diagnostic criteria, and the need of specific treatment for OIC that alleviate constipation while maintaining central analgesia are some of the main obstacles. These barriers alert us that underdiagnosis and undertreatment of OIC might be a frequent clinical issue among patients with OIC. Temporality is important for the differential diagnosis of OIC, therefore, inquiring patients regarding their bowel habits at the time of initiating opioid therapy, and during the treatment, would help to provide a more successful treatment for their patients with OIC symptoms. Introducing Rome IV diagnostic criteria in clinical practice is also essential.

\section{Treatments of opioid-induced constipation}

Although OIC is one of the most common causes of constipation in cancer patients, there are many other possible factors that can affect bowel movements and exacerbate constipation: cancer itself, cancer treatment, inactivity, poor fluid intake and nutrition, etc. Chemotherapy alters the intestinal microbiome resulting in reduced nucleotide and energy metabolism, cofactors and vitamins, signal transduction, and xenobiotic degradation as well as increased glycan metabolism [22]. This dysbiosis may be one of the mechanisms for chemotherapy mucositis, weight loss, and constipation. When making treatment decisions for OIC, all this potential etiologies and combinations of causes should be taken into consideration.

Anticipating and preventing OIC or treating it when it is mild is always easier. Once constipation is established, management can be much more difficult.

First-line treatments for OIC typically involve laxatives, increased dietary fiber, fluid intake, and exercise; however, these are associated with limited efficacy and do not address the underlying mechanism of OIC [3]. Therefore, implementation of new strategies should focus on more specific and targeted OIC treatment to provide a more satisfactory OIC management in patients with cancer. Furthermore, concomitant therapeutic strategies using traditional therapies and a more specific OIC treatment might be necessary when functional constipation and OIC overlapped.

Prevention and treatment of constipation

\section{Dietary fiber and exercise}

There is little evidence that healthy lifestyle changes and exercise improve OIC symptoms; however, data from functional constipation has traditionally been extrapolated to these patients. In healthy subjects, physical activity reduces colon 
transit time by stimulating colorectal motility. In patients with chronic idiopathic constipation, moderate physical activity 30-60 min per day improves the consistency of stools [23]. Adequate fluid intake is important to promote normal bowel function. However, patients with OIC would not benefit from additional dietary fiber unless their current intake is deficient. If fiber is excessively increased, it might put these patients at risk for bowel obstruction due to the decreased peristalsis, delayed gastric emptying, and prolonged intestinal transit time that occur with OIC [24]. Additionally, side effects of fiber mainly include the production of gas causing abdominal discomfort and flatulence. Soluble fiber pectins, guar, and ispaghula produce viscous solutions in the gastrointestinal tract that slow absorption in the small intestine. This may reduce the absorption of cholesterol and inhibit the activity of the pancreatic enzyme and the digestion of protein, leading to an anti-nutritive effect.

\section{Laxatives}

The routine prescription of laxatives for prophylaxis and treatment of intestinal dysfunction induced by opioids in cancer patients is recommended by the European Society of Medical Oncology (ESMO) [25•] and by the European Expert Consensus [26], that indicates that prophylactic treatment of OIC with laxatives can be considered, although more supporting evidence is needed.

Laxatives have shown to be effective to manage functional constipation, but OIC and functional constipation have different physio-pathological mechanism [27]. Laxatives may help defecation trough localized effects in the colon, but do not directly address the spectrum of the underlying mechanisms of OIC. There is limited evidence of laxative efficacy in the treatment of OIC. No randomized, controlled, double-blinded trials investigating the efficacy of conventional laxatives in OIC patients have shown superiority of one laxative over the other [28]. A prospective open-label study has suggested that polyethylene glycol and sodium picosulfate might be better than lactulose for cancer patients with opioids [29]. Various studies have demonstrated that laxatives do not alleviate OIC symptoms in some patients and may be associated with adverse events such as bloating, flatulence, sudden urge to defecate, electrolyte imbalances, dehydration and bowel obstruction, which can affect daily activities $[3,30]$.

Table 1 shows the benefits and side effects of the laxatives investigated in patients with OIC.

A study by Kumar et al. [36] observed that $54 \%$ of patients being treated with opioids and laxatives did not achieve the desired level of symptom (constipation) improvement more than half the time.

A failure of laxative treatment can be determined by a BFI score $>30$ points, and OIC treatment with PAMORA can be considered $[25 \bullet, 26]$.

\section{Drugs for opioid-induced constipation}

Several recent treatment guidelines recommend taking into account therapies based on peripherally acting opioid antagonists when starting opioid therapy or in patients with OIC who do not respond to laxatives $[25 \bullet, 26,28]$. In the process of drug development, the initial strategy was to investigate the use of the $\mu$-opioid receptor antagonist naloxone for the treatment of OIC [37]. 


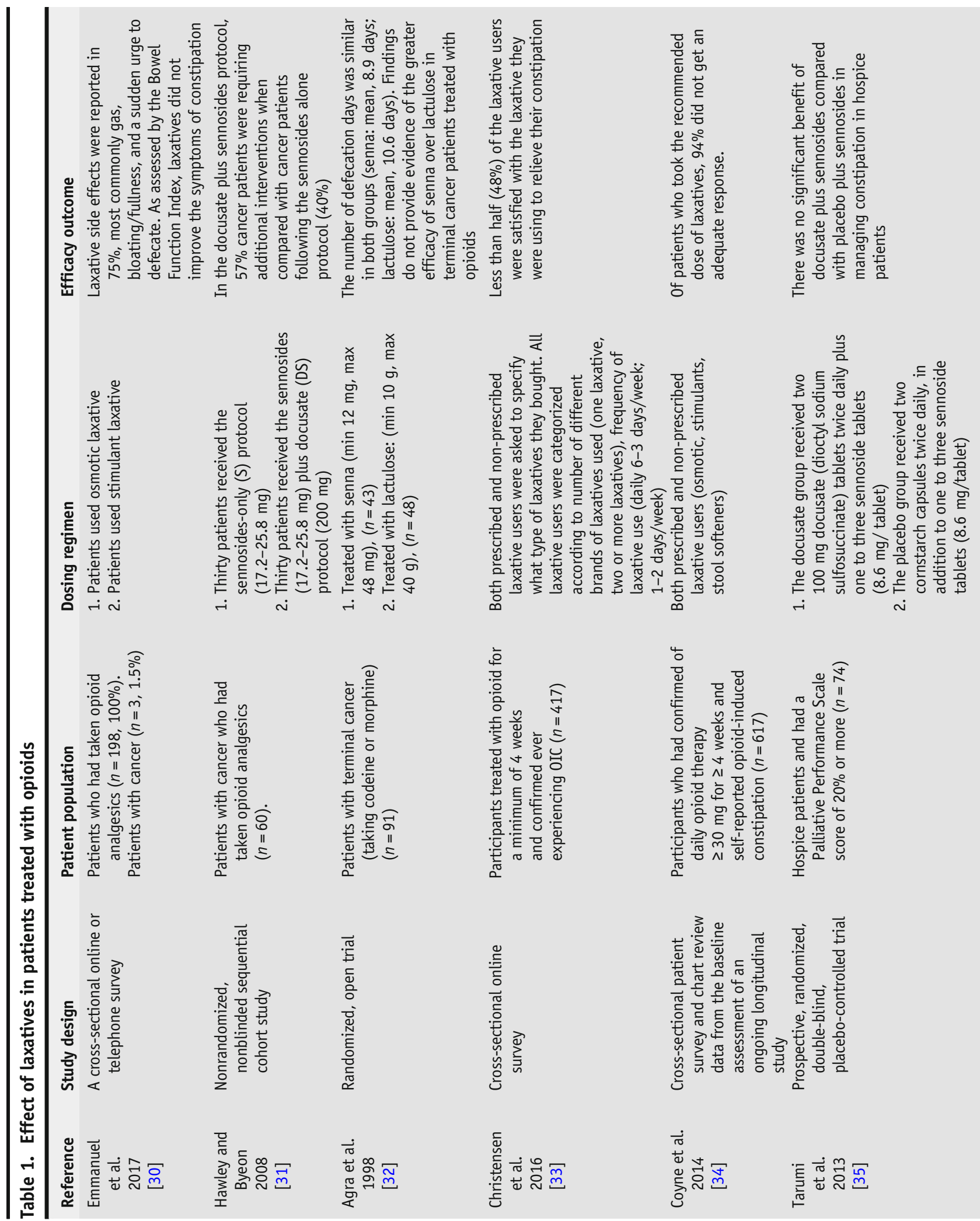




\section{Peripherally acting $\mu$-opioid receptor antagonists}

The objective of PAMORAs treatment is to reestablish intestinal function. PAMORAs bind exclusively to the peripheral $\mu$-opioid receptors avoiding opioid union to them. The therapeutic mechanisms of action imply a selective and competitive binding of the drug to the enteric $\mu$-opioid receptors [38]. PAMORAs are the best option treatment to alleviate OIC symptoms without affecting central analgesia [38]. Available PAMORAs include naltrexone, alvimopan, methylnaltrexone, naloxegol, and naldemedine. All PAMORAs have demonstrated efficacy in the treatment of OIC [36]. Rauck et al. [39], in a randomized, double-blind trial showed that oral formulation of methylnaltrexone is efficacious and well-tolerated for OIC. Naldemedine is a novel PAMORA recently approved for the treatment of OIC [40-45]. Spontaneous BM is achieved earlier with naldemedine (16.1 or $18.3 \mathrm{~h})$ than with placebo ( 46.7 or $45.9 \mathrm{~h}$, respectively) [41]. Song et al. [43] in a meta-analysis have suggested that naldemedine can improve the number of patients achieving spontaneous BM and its frequency. Furthermore, authors reported a higher incidence of serious adverse events in patients receiving naldemedine than placebo, mainly in cancer patients.

Merchan et al. [46] in a recent study compared the effectiveness and safety of oral naloxone versus subcutaneous methylnaltrexone in a medical intensive care unit. Both agents showed similar results on efficacy and safe. The time to first $\mathrm{BM}$ for oral naloxone and subcutaneous methylnaltrexone were 30 and $24 \mathrm{~h}$.

\section{Naloxegol}

Naloxegol is a PEGylated derivative of the opioid antagonist naloxone [4, 38]. Pegylation converts naloxegol to a substrate for the p-glycoprotein transporter (P-gp); this reduces central passive permeability compared with naloxone. Due to the reduction in permeability and the increase in the flow of naloxegol through the hematoencephalic barrier, related to the P-gp transporter, the penetration of the naloxegol into the central nervous system is negligible. It was shown that cerebral entry with naloxegol was insignificant as it did not modify morphine-induced miosis in 47 of 48 patients being treated with oral naloxegol [47]. Naloxegol antagonizes the $\mu$-receptor in the GI tract, decreasing the OIC effects without reversing the central analgesic effect [38]. Naloxegol have shown to mitigate the gastric peristaltic effects of morphine without significantly affecting analgesia [38]. Naloxegol has shown to be effective not only against placebo but also by indirect comparisons with other interventions, and naloxegol has been neither associated with an increased risk of severe adverse events nor with a reduction in analgesia of background opioid analgesic drug [38]. Most relevant studies of naloxegol are shown in Table 2.

The Ki values of naloxegol at the cloned human $\mu$-opioid receptor ranged from 6.5 to $8.5 \mathrm{nM}$. The pKi values of naloxegol and methylnaltrexone corresponded to respective geometric mean Ki values of $7.42 \mathrm{nM}$ and $22.1 \mathrm{nM}$, showing that naloxegol bound human $\mu$-opioid receptors with three-fold greater affinity than methylnaltrexone [47]. Floettmann et al. $[48 \bullet \bullet$ ] described the results of several studies that employed standard pharmacologic measures of opioid activity and pharmacokinetic measures of CNS and 


\section{Table 2. Summary of the most relevant naloxegol studies. Details of relevant naloxegol studies}

\begin{tabular}{|c|c|c|}
\hline Author/year & Webster et al. 2013 [49] & Chey et al. 2014 [50] \\
\hline Phase & II & III \\
\hline $\mathrm{N}$ & $\begin{array}{c}N=207 ; \geq 18 \text { years old; oral } \\
\text { morphine } 30-1000 \mathrm{mg}\end{array}$ & $\begin{array}{l}\text { KODIAC-04 } N=652 ; \text { KODIAC-05 } N=700 ; \\
\text { 18-84 years old; oral morphine } \\
\text { 30-1000 mg }>4 \text { weeks with good pain } \\
\text { control and no cancer diagnosis, GI } \\
\text { obstruction or increased risk for bowel } \\
\text { perforation who had confirmed, active OIC }\end{array}$ \\
\hline $\begin{array}{l}\text { Study design } \\
\text { and dosing }\end{array}$ & $\begin{array}{l}\text { Multicenter, randomized, DB, placebo-controlled, } \\
\text { dose-escalation; } 5 \mathrm{mg}, 25 \mathrm{mg} \text {, and } 50 \mathrm{mg} \\
\text { orally in sequential cohorts with placebo-control }\end{array}$ & $\begin{array}{l}\text { Multicenter, randomized, DB, parallel-group, } \\
\text { placebo-controlled. Naloxegol } 12.5 \mathrm{mg} \text {, } \\
25 \mathrm{mg} \text {, or placebo for } 12 \text { weeks }\end{array}$ \\
\hline $\mathrm{AE}$ & $\begin{array}{l}\text { Abdominal pain, diarrhea, and nausea with } \\
\text { increased frequency and severity in } 50 \mathrm{mg} \\
\text { group; no evidence of opioid withdrawal } \\
\text { or worsening pain }\end{array}$ & $\begin{array}{l}\text { Diarrhea, abdominal pain, nausea, vomiting; } \\
\text { no evidence of opioid withdrawal or } \\
\text { worsening pain. More common in } \\
25 \text { mg group }\end{array}$ \\
\hline $\begin{array}{l}\text { Variables efficacy } \\
\text { and outcomes }\end{array}$ & $\begin{array}{l}\text { Primary endpoint: } \\
\text {-Change in spontaneous bowel movements (BMs)/ } \\
\text { week over baseline at the end of week } 1 \text { statistically } \\
\text { significantly improved compared with placebo at } \\
25 \mathrm{mg} \text { and } 50 \mathrm{mg} \text { doses } \\
\text { Secondary endpoints: } \\
\text {-Change over baseline across weeks } 2,3 \text {, and } 4 \\
\text {-Change over baseline at the end of week } 4 \\
\text {-Time after first dose of naloxegol to first laxation } \\
\text {-Improvement over baseline compared with } \\
\text { placebo maintained in } 25 \mathrm{mg} \text { and } 50 \mathrm{mg} \\
\text { cohort over } 4 \text { weeks. }\end{array}$ & $\begin{array}{l}\text { Primary endpoint: } \\
\text {-Twelve-week response rate ( } \geq 3 \text { spontaneous } \\
\text { BMs/week and } \geq 1 \text { spontaneous } \\
\text { BMs over baseline for } \geq 9 / 12 \text { weeks and } \geq 3 / 4 \\
\text { of the final weeks) } \\
\text { - Higher response for } 25 \mathrm{mg} \text { group over } \\
\text { placebo for both trials and for } 12.5 \mathrm{mg} \\
\text { group over placebo in KODIAC-04 trial }\end{array}$ \\
\hline
\end{tabular}

demonstrated that naloxegol relieves OIC-associated symptoms in patients with chronic noncancer pain.

Naloxegol does not significantly inhibit the activity of CYP1A2, CYP2C9, CYP2D6, CYP3A4, CYP2C19, P-glycoprotein, breast cancer resistance protein, organic anion-transporter (OAT)1, OAT3, organic cation transporter-2, organic anion-transporting polypeptide (OATP)1B1, or OATP1B3, nor does it significantly induce the activity of CYP1A2, CYP2B6, or CYP3A4 [41].

A pooled analysis [51] of patients being treated with laxatives for 4 days showed that those with an inadequate response to one or more types of laxatives had response rates of $42.5 \%$ and $47.7 \%$ for naloxegol 12.5 and $25 \mathrm{mg} /$ day vs those receiving a placebo $(30.1 \%)(p=0.005$ and $p<=0.001$, respectively) and those with an inadequate response to two or more types of laxatives had response rates of $44.3 \%$ and $44.4 \%$ versus $30.0 \%$, respectively (both $p=0.05$ ).

To rule out any adverse cardiac events noted with its predecessor alvimopan, an additional trial was conducted (NCT01325415). A randomized, placebo- 
controlled crossover thorough the QT/QTC study with therapeutic (25 mg) and supratherapeutic (150 mg) naloxegol or moxifloxacin $400 \mathrm{mg}$ or placebo in health volunteers demonstrated no significant cardiovascular changes [52]. In addition, a new clinical trial (NCT03087708) was started in University of Minnesota, to determine feasibility and safety of long-term administration of two doses of naloxegol in patients with advanced NSCLC receiving first-line pemetrexed-based chemotherapy.

Naloxegol has been approved in the European Union for any patient (cancer patient and noncancer patient) suffering with OIC and with an inadequate response to at least one laxative after at least 4 days treatment in the 2 weeks previous to the diagnosis.

In addition SEOM recommend the use of naloxegol in cancer patients with OIC and an inadequate response to first-line treatments (e.g., dietary changes

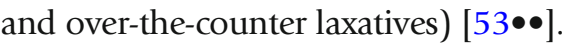

\section{Additional agents and mechanisms to OIC control}

Linaclotide is a peptide agonist of the guanylate cyclase- $\mathrm{C}$ receptor involved in the intracellular conversion of guanosine 5-triphosphate to cyclic guanosine monophosphate [54]. Linaclotide has been shown to be an effective and well-tolerated agent for the treatment of chronic constipation [55-58]. Lubiprostone is a specific activator of the type 2 chloride channels at the intestinal epithelium whose activity increases the liquidity of contents [59]. Compared with placebo, lubiprostone has demonstrated to increase spontaneous $\mathrm{BM}$ frequency and response rate, and to improve OIC-related symptoms [60-64]. Prucalopride is a highly selective serotonin receptor agonist showing gastrointestinal prokinetic activity. Prucalopride has demonstrated activity in chronic constipation, and European guidelines actually recommend its use [56].

\section{Conclusion}

Pain is a major problem in all stages of cancer. Analgesic drugs are used to manage chronic pain and as part of a multifaceted focus that integrates strategies with an interventionist, psychological, physical, or complementary approach, seeking to improve the treatment of pain and enabling rehabilitation. A common consequence of opiate use, due to the distribution of $\mu$-receptors, is OIC.

Although the evidence is limited and may present some contraindications, the routine prescription of laxatives is recommended for patients who receive opioid analgesia. In some studies, it can be observed that laxatives do not address OIC symptoms in some patients and can cause adverse events that affect daily activities such as bloating, flatulence, and a sudden urge to defecate. Furthermore, laxatives assist defecation through localized effects in the colon, while OIC arises following stimulation of the enteric $\mu$-opioid receptors. Although traditional treatment such as laxatives or the increase of dietary fiber is often insufficient to relieve OIC symptoms, a series of new and more specific pharmacological approaches have emerged. Several treatment guidelines recommend taking into account strategic therapies based on PAMORAs when starting opioid therapy or in patients with OIC who do not respond to laxatives. 
Among currently available PAMORAs, daily administration of oral naloxegol seems to be the most appropriate. Naloxegol is effective for the treatment of OIC who do not respond to traditional laxatives. Naloxegol has shown response rates significantly higher versus placebo in the overall patient population and in patients classified as laxativeinadequate responder treated with $25 \mathrm{mg}$ for both studies and $12.5 \mathrm{mg}$ for one study, in two randomized, placebo-controlled, phase 3 trials.

Naloxegol present a well-tolerated safety profile. Adverse events are more frequently GI and mild to moderate in severity and occurred at the time of initiation of naloxegol treatment. Severe adverse events are rare, and no bowel perforation has been reported, differing of what was noticed in seven patients treated with subcutaneously administered methylnaltrexone.

Altogether, naloxegol should be considered as an important alternative for the treatment of OIC in cancer patients. Future research should address whether naloxegol is more efficacious by its comparison directly with first-line treatments, including laxatives.

\section{Acknowledgment}

Authors would express gratitude to Meisys for helping in the elaboration of the manuscript.

\section{Compliance with Ethical Standards}

\section{Conflict of interest}

Ricard Mesía has received compensation from Merck, Bristol-Myers Squibb, MSD, Kyowa, AstraZeneca, Nanobiotix, and Roche for Service as a consultant. Juan Antonio Virizuela declares that he has no conflict of interest. Jose Gómez declares that he has no conflict of interest. Tamara Sauri declares that she has no conflict of interest. Gloria Serrano declares that she has no conflict of interest. Eduardo Pujol declares that he has no conflict of interest.

This work was supported by Kyowa Kirin Farmaceutica SLU. The authors received research funding from Kyowa Kirin Farmaceutica SLU for this colaboration.

\section{Human and animal rights and informed consent}

All reported studies/experiments with human or animal subjects performed by the authors have been previously published and complied with all applicable ethical standards (including the Helsinki Declaration and its amendments, institutional/national research committee standards, and international/national/ institutional guidelines).

\section{Open Access}

This article is distributed under the terms of the Creative Commons Attribution 4.0 International License (http://creativecommons.org/licenses/by/4.0/), which permits unrestricted use, distribution, and reproduction in any medium, provided you give appropriate credit to the original author(s) and the source, provide a link to the Creative Commons license, and indicate if changes were made. 
Papers of particular interest, published recently, have been highlighted as:

- Of importance

- Of major importance

1. Escobar Álvarez Y, Rodríguez Sánchez CA, Caballero Martínez F, Recuero Cuervo V, Camps Herrero C. Professional survey on knowledge and clinical patterns of pain management in Spanish medical oncology. Clin Transl Oncol. 2010;12(12):819-24.

2. Porta-Sales J, Nabal-Vicuna M, Vallano A, Espinosa J, Planas-Domingo J, Verger-Fransoy E, et al. Have we improved pain control in cancer patients? A multicenter study of ambulatory and hospitalized cancer patients. J Palliat Med. 2015;18(11):923-32.

3. Bell TJ, Panchal SJ, Miaskowski C, Bolge SC, Milanova $\mathrm{T}$, Williamson R. The prevalence, severity, and impact of opioid-induced bowel dysfunction: results of a US and European patient survey (PROBE 1). Pain Med. 2009;10:35-42.

4. Larkin PJ, Cherny NI, La Carpia D, Guglielmo M, Ostgathe C, Scotté F, et al. Diagnosis, assessment and management of constipation in advanced cancer: ESMO Clinical Practice Guidelines. Ann Oncol. 2018;29:iv111-25.

5. Brenner DM, Stern E, Cash BD. Opioid-related constipation in patients with non-cancer pain syndromes: a review of evidence-based therapies and justification for a change in nomenclature. Curr Gastroenterol Rep. 2017;19(3):12.

6. Deandrea S, Montanari M, Moja L, Apolone G. Prevalence of undertreatment in cancer pain. A review of published literature. Ann Oncol. 2008;19:1985-91.

7. van den Beuken-van Everdingen MHHL, Joosten EA, Tjan-Heijnen VC, Janssen DJ. Update on prevalence of pain in patients with cancer: systematic review and meta-analysis. J Pain Symptom Manag. 2016;51(6):1070-90.

8. Portenoy RK. Treatment of cancer pain. Lancet. 2011;377(9784):2236-47.

9. Ganzer H, Touger-Decker R, Byham-Gray L, Murphy BA, Epstein JB. The eating experience after treatment for head and neck cancer: a review of the literature. Oral Oncol. 2015;51(7):634-42.

10. Benyamin R, Trecot AM, Datta S, Buenaventura R, Adlaka R, Sehgal N, et al. Opioid complications and side effects. Pain Physician. 2008;11(2):105-20.

11. Azizi Z, Javid Anbardan S, Ebrahimi Daryani N. A review of the clinical manifestations, pathophysiology and management of opioid bowel dysfunction and narcotic bowel syndrome. Middle East J Dig Dis. 2014;6:5-12.

12. Thomas J. Opioid-induced bowel dysfunction. J Pain Symptom Manag. 2008;35(1):103-13.

13. Brock C, Olesen SS, Olesen AE, Frøkjaer JB, Andresen T, Drewes AM. Opioid-induced bowel dysfunction: pathophysiology and management. Drugs. 2012;72(14):1847-65.

14. Boswell K, Kwong WJ, Kavanagh S. Burden of opioidassociated gastrointestinal side effects from clinical and economic perspectives: a systematic literature review. J Opioid Manag. 2010;6:269-89.

15. Abramowitz L, Bezlaud N, Labreze L, Giardina V, Caussé C, Chuberre B, et al. Prevalence and impact of constipation and bowel dysfunction induced by strong opioids: a cross-sectional survey of 520 patients with cancer pain: DYONISOS study. J Med Econ. 2013;16(12):1423-33.

16. Gálvez R, Provencio M, Cobo M, Pérez C, Pérez C, Canal J. Observational and cross-sectional study of prevalence and severity of the opioid-induced bowel dysfunction. Aten Primaria. 2014;46(1):32-9.

17. Gaertner J, Siemns W, Camilleri M, Davies A, Drossman DA, Webster LR, et al. Definitions and outcome measures of clinical trials regarding opioidinduced constipation: a systematic review. J Clin Gastroenterol. 2015;49(1):9-16.

18. Ueberall M, Müller-Lissner S, Buschmann-Kramm C, Bosse B. The bowel function index for evaluating constipation in pain patients: definition of a reference range for a non-constipated population of pain patients. J Int Med Res. 2011;39(1):41-50.

19. Argoff CE, Brennan MJ, Camilleri M, Davies A, Fudin J, Galluzzi KE, et al. Consensus recommendations on initiating prescription therapies for opioid-induced constipation. Pain Med. 2015;16(12):2324-37.

20. Camilleri M, Lembo K, Drossman DA. Opioids in gastroenterology: treating adverse effects and creating therapeutic benefits. Clin Gastroenterol Hepatol. 2017;15:1338-49.

21. Camilleri M, Drossman DA, Becker G, Webster LR, Davies AN, Mawe GM. Emerging treatments in neurogastroenterology: a multidisciplinary working group consensus statement on opioid-induced constipation. Neurogastroentol Motil. 2014;26:1386-95.

22. Montassier E, Gastinne T, Vangay P, Al-Ghalith GA, Bruley des Varannes S, Massart S, et al. Chemotherapydriven dysbiosis in the intestinal microbiome. Aliment Pharmacol Ther. 2015;42(5):515-28.

23. Krogh K, Chiarioni G, Whitehead W. Management of chronic constipation in adults. United European Gastroenterol J. 2017;5:465-72.

24. Leppert $\mathrm{W}$. The impact of opioid analgesics on the gastrointestinal tract function and the current management possibilities. Contemp Oncol. 2012;16:125-31.

25. Fallon M, Giusti R, Aielli R, Hoskin P, Rolke R, Sharma $\mathrm{M}$, et al. Management of cancer pain in adult patients: ESMO Clinical Practice Guidelines. Ann Oncol. 
2018;29(4):iv166-91. https://doi.org/10.1093/ annonc/mdy 152.

ESMO Clinical Practice Guidelines that recommend the prescription of laxatives for prophylaxis and treatment of intestinal dysfunction induced by opioids in cancer patients.

26. Farmer AD, Drewes AM, Chiarioni G, De Giorgio R, O'Brien T, Morlion B, et al. Pathophysiology and management of opioid-induced constipation: European expert consensus statement. United European Gastroenterol J. 2019;7(1):7-20.

27. Holzer P. Opioid receptors in the gastrointestinal tract Regul Pept. 2009;155(1-3):11-7.

28. Drewes AM, Munkholm P, Simrén M, Breivik $H$, Kongsgaard UE, Hatlebakk JG, et al. Definition, diagnosis and treatment strategies for opioid-induced bowel dysfunction-recommendations of the Nordic working group. Scand J Pain. 2016;11:111-22.

29. Candy BJL, Goodman ML, Drake R, Tookman A. Laxatives or methylnaltrexone for the management of constipation in palliative care patients. Cochrane Database Syst Rev. 2011;1:CD003448.

30. Emmanuel A, Johnson M, McSkimming P, Dickerson S. Laxatives do not improve symptoms of opioidinduced constipation: results of a patient survey. Pain Med. 2017;18(10):1932-40.

31. Hawley PH, Byeon JJ. A comparison of sennosidesbased bowel protocols with and without docusate in hospitalized patients with cancer. J Palliat Med. 2008;11(4):575-81.

32. Agra Y, Sacristan A, Gonzalez M, et al. Efficacy of senna versus lactulose in terminal cancer patients treated with opioids. J Pain Symptom Manag. 1998;15:1-7.

33. Christensen HN, Olsson U, From J, Breivik H. Opioidinduced constipation, use of laxatives, and healthrelated quality of life. Scand J Pain. 2016;11:104-10.

34. Coyne KS, LoCasale RJ, Datto CJ, Sexton CC, Yeomans $\mathrm{K}$, Tack J. Opioid-induced constipation in patients with chronic non-cancer pain in the USA, Canada, Germany, and the UK: descriptive analysis of baseline patientreported outcomes and retrospective chart review. Clinicoecon Outcomes Res. 2014;6:269-81.

35. Tarumi Y, Wilson MP, Szafran O, Spooner GR. Randomized, double-blind, placebocontrolled trial of oral docusate in the management of constipation in hospice patients. J Pain Symptom Manag. 2013;45(1):213.

36. Kumar L, Barker C, Emmanuel A. Opioid-induced constipation: pathophysiology, clinical consequences, and management. Gastroenterol Res Pract. 2014;2014:6.

37. Liu M, Wittbrodt E. Low-dose oral naloxone reverses opioid-induced constipation and analgesia. J Pain Symptom Manag. 2002;23(1):48-53.

38. Poulsen JL, Brock C, Olesen AE, Nilsson M, Drewes AM. Clinical potential of naloxegol in the management of opioid-induced bowel dysfunction. Clin Exp Gastroenterol. 2014;7:345-58.

39. Rauck R, Slatkin NE, Stambler N, Harper JR, Israel RJ. Randomized, double-blind trial of oral methylnaltrexone for the treatment of opioid-induced constipation in patients with chronic noncancer pain. Pain Pract. 2017;17(6):820-8.

40. Markham A. Naldemedine: First Global Approval. Drugs. 2017;77:923-7.

41. Wild J, Yamada T, Arjona Ferreira JC, Hale M. Onset of action of naldemedine in the treatment of opioidinduced constipation in patients with chronic noncancer pain: results from 2 randomized, placebocontrolled, phase 3 trials. Pain. 2019;160:2358-64.

42. Watari R, Matsuda A, Ohnishi S, Hasegawa H. Minimal contribution of P-gp on the low brain distribution of naldemedine, a peripherally acting mu-opioid receptor antagonist. Drug Metab Pharmacokinet. 2019;34(2):126-33

43. Song X, Wang D, Qu X, Dong N, Teng S. A metaanalysis of naldemedine for the treatment of opioidinduced constipation. Expert Rev Clin Pharmacol. 2019;12(2):121-8.

44. Saito Y, Yokota T, Arai M, Tada Y, Sumitani M. Naldemedine in Japanese patients with opioidinduced constipation and chronic noncancer pain: open-label phase III studies. J Pain Res. 2019;12:12738.

45. Ohnishi S, Fukumura K, Kubota R, Wajima T. Absorption, distribution, metabolism, and excretion of radiolabeled naldemedine in healthy subjects. Xenobiotica. 2019;49(9):1044-53.

46. Merchan C, Altshuler D, Papadopoulos J. Methylnaltrexone versus naloxone for opioid-induced constipation in the medical intensive care unit. Ann Pharmacother. 2017;51(3):203-8.

47. Neumann T, Van Patischen H, Marcantonio A, Song D, Morrison P, Eldon M. Evaluation of single oral doses of NKTR118 (PEG-Naloxol) as a peripheral opioid antagonist (POA): a double-blind placebo-controlled study in healthy male subjects. J Clin Pharmacol. 2007;47:1210.

48.• Floettmann E, Bui K, Sostek M, Payza K, Eldon M. Pharmacologic profile of naloxegol, a peripherally acting $\mu$-Oopioid receptor antagonist, for the Ttreatment of opioid-induced constipation. J Pharmacol Exp Ther. 2017;361(2):280-91.

This article describes the results of several studies that employed standard pharmacologic measures of opioid activity and pharmacokinetic measures of the central nervous system (CNS) demonstrating that naloxegol relieves OIC-associated symptoms in patients with chronic noncancer pain.

49. Webster L, Dhar S, Eldon M, Masuoka L, Lappalainen J, Sostek M. A phase 2, double-blind, randomized, placebo-controlled, dose-escalation study to evaluate the efficacy, safety, and tolerability of naloxegol in patients with opioid-induced constipation. Pain. 2013;154(9):1542-50.

50. Chey WD, Webster L, Sostek M, Lappalainen J, Barker PN, Tack J. Naloxegol for opioid-induced constipation in patients with noncancer pain. $\mathrm{N}$ Engl J Med. 2014;370(25):2387-96. 
51. Tack J, Lappalainen J, Ulysses D, Tummala R, Sostek M. Efficacy and safety of naloxegol in patients with opioid-induced constipation and laxative-inadequate response. United European Gastroenterol J.

2015;3(5):471-80.

52. Gottfridsson C, Carlson G, Lappalainen J, Sostek M. Evaluation of the effect of naloxegol on cardiac repolarization: a randomized, placebo- and positivecontrolled crossover thorough QT/QTc study in healthy volunteers. Clin Ther. 2013;35(12):1876-83.

53.• Jara C, Del Barco S, Grávalos C, Hoyos S, Hernández B, Muñoz M, et al. SEOM clinical guideline for treatment of cancer pain (2017). Clin Transl Oncol. 2017;20(1):97-107.

An update of the SEOM guide thatrecommend the use of naloxegol in cancer patients with OIC and an inadequate response to first-line treatments.

54. Bassotti G, Usai-Satta P, Bellini M. Linaclotide for the treatment of chronic constipation. Expert Opin Pharmacother. 2018;19:1261-6.

55. Sonu I, Triadafilopoulos G, Gardner JD. Persistent constipation and abdominal adverse events with newer treatments for constipation. BMJ Open Gastroenterol. 2016;3(1):e000094.

56. Pannemans J, Vanuytsel T, Tack J. New developments in the treatment of opioid-induced gastrointestinal symptoms. United European Gastroenterol J. 2018;6(8):1126-35.

57. Andresen V, Layer P. Medical therapy of constipation: current standards and beyond. Visc Med.

2018;34(2):123-7.

58. Sera L, McPherson ML. Management of opioidinduced constipation in hospice patients. Am J Hosp Palliat Care. 2018;35(2):330-5.

59. Webster LR, Brewer RP, Lichtlen P, Losch-Beridon T, Mareya S, Wang M. Efficacy of lubiprostone for the treatment of opioid-induced constipation, analyzed by opioid class. Pain Med. 2018;19(6):1195-205.

60. Viscusi ER. Clinical overview and considerations for the management of opioid-induced constipation in patients with chronic noncancer pain. Clin J Pain. 2019;35(2):174-88.

61. Nee J, Zakari M, Sugarman MA, Whelan J, Hirsch W, Sultan S, et al. Efficacy of treatments for opioidinduced constipation: systematic review and metaanalysis. Clin Gastroenterol Hepatol. 2018;16(10):1569-84.

62. Murphy JA, Sheridan EA. Evidence based review of pharmacotherapy for opioid-induced constipation in noncancer pain. Ann Pharmacother. 2018;52(4):370-9.

63. Spierings ELH, Drossman DA, Cryer B, Jamal M, LoschBeridon T, Mareya SM, et al. Efficacy and safety of lubiprostone in patients with opioid-induced constipation: phase 3 study results and pooled analysis of the effect of concomitant methadone use on clinical outcomes. Pain Med. 2018;19(6):1184-94.

64. Sridharan K, Sivaramakrishnan G. Drugs for treating opioid-induced constipation: a mixed treatment comparison network meta-analysis of randomized controlled clinical trials. J Pain Symptom Manag. 2018;55(2):468-79.

\section{Publisher's note}

Springer Nature remains neutral with regard to jurisdictional claims in published maps and institutional affiliations. 